\title{
Quilombo Campinho da Independência, Paraty (RJ): território étnico e a luta por uma educação diferenciada
}

\author{
CARVALHO, Ediléia ${ }^{1}$ \\ CIRQUEIRA, Diogo Marçal ${ }^{2}$
}

\section{RESUMO}

Este artigo objetiva contribuir para o tema da educação escolar quilombola. Para tanto se debruça sobre a história da comunidade Campinho da Independência, Paraty, RJ ao protagonizar uma experiência de educação diferenciada calcada na pedagogia do seu território. A coleta de dados ocorreu entre os anos de 2012 e 2019 e contou com: etnografia; entrevistas com as principais lideranças políticas das comunidades pesquisadas; análise de documentos oficiais disponíveis na escola e Secretaria Municipal de Educação. A experiência aqui investigada deriva de uma demanda comunitária acionada por uma política educacional específica, diferenciada e fragilizada em tempo tão algozes. Dessa forma, diante de um cenário político marcado pelo retrocesso de algumas dessas políticas, que vinham consolidando-se em governos anteriores, compreendemos que a experiência aqui trazida reflete processos de luta contra-hegemônica e decoloniais à medida que são protagonizadas de e a partir de sujeitos "Outros", que sofreram uma história de submissão e subalternização.

Educação escolar quilombola. Território Quilombola. Educação Diferenciada. Quilombos.

Quilombo Campinho De Independência, Paraty (Rj): Ethnic Territory And The Fight For A Differentiated Education

\section{ABSTRACT}

This article aims to contribute to the theme of quilombola school education. In order to do so, it focuses on the history of struggle and resistance of the Campinho da Independência community in Paraty, Rio de Janeiro, Brazil, as a differentiated education experience based on the pedagogy of its territory. The data collection took place between the years of 2012 and 2019 and counted on: ethnography; interviews with the main political leaders of the communities surveyed; analysis of official documents available at the school and Municipal Department of Education. The experience investigated here derives from a community demand triggered by a specific educational policy, differentiated and weakened in times so bad. Thus, in the face of a political scenario marked by the regression of some of these policies, which were consolidating in previous governments, we understand that the experience brought here reflects

\footnotetext{
${ }^{1}$ Doutora no Programa de Pós-graduação em Educação da PUC-RIO- Educadora na Ong Novamerica. E-mail: dilacarvalho@gmail.com

2 Professor Doutor, no Departamento de Geografia e Políticas Públicas no IEAR-UFF - E-mail: diogomc@id.uff.br
} 
Quilombo Campinho Da Independência, Paraty (Rj):

território étnico e a luta por uma educação diferenciada

processes of counter-hegemonic and decolonial struggle as they are carried out in and out of subjects "Others", who suffered a history of submission and subalternization.

\section{Quilombola school education. Quilombola Territory. Differentiated Education. Quilombos.}

\section{INTRODUÇÃO}

No ano de 2018 completamos trinta anos da inserção do Artigo 68 na Constituição Federal de 1988, cuja designação prevê "aos remanescentes das comunidades dos quilombos que estejam ocupando suas terras é reconhecida a propriedade definitiva, devendo o Estado emitir-lhes os títulos respectivos". Nesse ínterim, um "campesinato negro" (GOMES, 2015; NASCIMENTO, 1982) acossado por uma série de atores hegemônicos ligados ao capital se apropriou dessa "benesse" jurídica e a agenciou para defender seus territórios. Se antes de 1888, onde alcançou o sistema escravista no Brasil, formaram-se quilombos e mocambos, nos dias atuais aonde o voraz agronegócio e seus congêneresmineração, especulação imobiliária, grilagem, barragens hidrelétricas etc. chegam, (re)nascem quilombos. Camponeses negros resistem e protagonizam ações contra esses grupos que tentam usurpar seus territórios. Não por acaso, em praticamente todas as partes do Brasil existem quilombos, algo que chega a cifra de cinco mil comunidades espalhados por todas as regiões (ANJOS, 2009, 2011).

Estes grupos, mediante os princípios jurídicos do Art. 68, "ressemantizam" a seu favor o sentido de quilombo na atualidade (ARRUTI, 2006). E se existe algo que marca a luta dessas comunidades desde a vigência do referido artigo de lei, é a diversidade de estratégias de enfrentamento pelo direito a terra e ao território. É neste sentido que o presente trabalho objetiva contribuir. Para isso, busca apresentar e analisar uma experiência empírica de luta em defesa do território protagonizada por quilombolas face à construção de um projeto de escola pautado nesse movimento. Nosso campo empírico neste trabalho é a experiência vivenciada pelo Quilombo Campinho da Independência, localizado em Paraty-RJ na luta por uma educação diferenciada, com vistas a ser implementada em sua escola local. (CARVALHO, 2016).

A escolha da referida comunidade se justifica por duas questões. Primeiramente por percebermos, no cenário estadual do Rio de Janeiro, o seu destaque no movimento de luta pela escola quilombola junto ao seu município. Segundo, porque compreendemos que a experiência vivenciada pelo Campinho da Independência aponta dilemas e estratégias singulares que nos auxiliam na reflexão sobre a pluralidade das emergentes demandas de educação escolar quilombola. 
Os procedimentos metodológicos adotados para o desenvolvimento deste trabalho de cunho qualitativo são oriundos de uma pesquisa de mestrado e, posteriormente, de doutorado desenvolvidas entre os anos de 2012 e 2019 na interface da antropologia com a educação, que constou com as seguintes etapas: 1) análise dos documentos oficiais (nacionais, estaduais e/ou municipais) que remetem ao tema da educação para as relações étnico-raciais e da educação escolar quilombola; 2) análise bibliográfica sobre o alargado e ainda incipiente campo denominado educação escolar quilombola, campo este que abarca uma reflexão sobre as práticas educativas para além do contexto escolar; 3) pesquisa de campo na comunidade quilombola pesquisada, que aliou etnografia a entrevistas semiestruturadas com lideranças políticas, equipe escolar e equipe da Secretaria Municipal de Educação. Somam-se a este material de pesquisa, dados coletados no âmbito do Projeto de Reorientação Curricular em Escolas Quilombolas no município de Paraty no qual o quilombo Campinho da Independência faz parte. Fruto de um tratado de cooperação técnica entre o Instituto de Educação de Angra dos Reis (IEAR-UFF), Secretaria Municipal de Educação de Paraty e o Fórum de Comunidades Tradicionais da Região da Costa Verde, o projeto "Escolas do Território" articula ações pedagógicas e de formação em comunidades caiçaras, indígenas e quilombolas. O referido projeto tem por objetivo implementar um programa de formação continuada com os professores das unidades escolares inseridas nessas comunidades, subsidiando pedagogicamente o processo de construção de um currículo diferenciado e um movimento de reorientação curricular na rede municipal de Paraty-RJ. Isso muito em razão da aplicação nessas escolas de um currículo descontextualizado que, longe de proporcionar uma interação com o contexto local, executa um plano centrado na perspectiva do urbano e reproduz valores eurocêntricos e brancos em seu currículo e práticas pedagógicas.

Compreendemos que a apropriação do território não se limita a uma simples posse física e do controle das fronteiras (tendo em vista que o Quilombo do Campinho é uma comunidade titulada desde o ano de 1999). Os aspectos simbólicos do território também definem os processos de territorialidade. Dessa forma, as lideranças quilombolas lutam pela escola, pois sabem que a detenção e a manutenção do território dependem da reprodução e difusão de representações que estejam em consonância com as particularidades culturais, modo de vida, usos do solo, relação com a natureza etc. da própria comunidade. Assim, a escola e o tipo de educação reproduzida em seu interior se tornam componentes estratégicos para a manutenção (ou para o colapso) do território.

As reivindicações das lideranças do Campinho estão ancoradas justamente nas Diretrizes Curriculares Nacionais para a Educação Escolar Quilombola na Educação Básica (Resolução CNE/CEB 08/2012). A resolução assegura aos quilombolas uma educação diferenciada baseada em aspectos 
Quilombo Campinho Da Independência, Paraty (Rj): território étnico e a luta por uma educação diferenciada

como "memória coletiva", "marcos civilizatórios", "práticas culturais", "tecnologias e formas de produção do trabalho", "territorialidade" etc., existentes nas comunidades quilombolas. Assim, há a tentativa de agenciar o cotidiano e as práticas culturais existentes no Quilombo do Campinho como princípios norteadores na construção das práticas e do currículo na escola ali inserida.

O texto está organizado da seguinte forma: Primeiramente apresentaremos uma interpretação das diretrizes da Educação Escolar Quilombola e seus horizontes políticos; posteriormente será descrita e analisada a luta do Quilombo do Campinho por uma educação diferenciada; por fim, apresentaremos o processo de reorientação curricular em curso na Escola Municipal Campinho da Independência, seguido das considerações finais.

\section{Diretrizes Curriculares Nacionais para a Educação Escolar Quilombola e outras normativas vigentes}

As políticas educacionais que nascem da premissa do reconhecimento das diferenças étnicas e culturais representam uma conquista que resulta, sobretudo, de inúmeras iniciativas e lutas de movimentos e organizações sociais (Carpenedo 2011). Tal constatação desloca a ideia de que essas conquistas foram delegadas pelo Estado ou pela situação política, para a afirmação de que resultam, principalmente, de importantes movimentos de lutas, de resistência e de re-existência (WALSH, 2016).

Fruto da luta e do posicionamento político de diferentes atores sociais, essas políticas visam ao entendimento das diferentes demandas que emergem desse cenário de lutas e disputas políticas cada vez mais acirradas. É nesse contexto, por exemplo, que compreendemos a proporção que o tema das diferenças culturais tem ganhado no âmbito educacional, sobretudo no contexto de formulação das políticas públicas.

Podemos citar como exemplo dessas políticas, as Diretrizes Curriculares Nacionais para a Educação Escolar Quilombola (Brasil, 2012). Esta iniciativa, em conjunto com outras ações ${ }^{3}$ e circunstâncias - ainda que atualmente algumas se encontrem em estado de extinção- contribuiu/contribui para a ampliação do debate público e acadêmico acerca da educação escolar em comunidades quilombolas, subsidiando reflexões no intuito de trazer

\footnotetext{
${ }^{3}$ Como a criação da Secretaria de Políticas de Promoção da Igualdade Racial (Seppir), em 2003, e a Secretaria de Educação Continuada, Alfabetização e Diversidade (Secad) criada em 2004, atual Secadi (Secretaria de Educação Continuada, Alfabetização, Diversidade e Inclusão), desde 2011.
} 
legitimidade para a entrada de seus saberes, culturas e tradições nos currículos escolares (CARVALHO, 2016).

Mas, não há como falar dessas políticas sem mencionarmos o momento político complexo que estamos atravessando. Tomando emprestada a máxima do sociólogo Boaventura de Sousa Santos, um momento de "incerteza entre o medo e a esperança", de "incertezas abissais"4, que não deixam dúvidas quanto à arquitetura de um projeto de desmonte do Estado de Direitos. Um período marcado por retrocessos de toda ordem, afetando diretamente as políticas públicas que incidem diretamente na promoção de direitos diferenciados de determinados grupos sociais, como é o caso das comunidades remanescentes de quilombo.

Nesse cenário político instaurado, percebe-se que os povos tradicionais e do campo, por exemplo, são vistos como obstáculos à mercantilização da terra, aos avanços da monocultura e do capitalismo de uma forma geral. Questões estas, que reverberam explicitamente na luta política e simbólica da educação, uma vez que é cada vez mais recorrente percebermos a formulação de Projetos de Lei que visam projetar sobre a escola a mesma lógica branca, mercantilista, monocultural, homogeneizadora e acrítica.

Segundo dados do relatório da Educação Escolar Quilombola no Censo da Educação Básica, produzido pelo INEP no ano de 2015 (relatório mais recente), a educação escolar em áreas remanescentes de quilombo esteve e, em certa medida, é contemplada também na modalidade de educação do campo, com a qual comunga em princípios e questões comuns. Entretanto, por existirem elementos distintivos importantes, atrelados aos direitos étnicos desses grupos, ou seja, traços culturais que os diferenciam, foi preciso negar este viés homogeneizante das populações rurais, como até então era concebido na educação do campo e iniciar uma agenda pública e política sobre as especificidades das comunidades quilombolas que deveriam ser contempladas, também no campo da educação.

Diante deste reconhecimento acerca das especificidades destes grupos, segmentos dos movimentos sociais negros iniciam, a partir da década de 1980, uma série de debates onde já se discutia a função social das escolas que atendem essas comunidades. Com base nesta premissa, o I Encontro Nacional Quilombola que ocorreu no ano de $1995^{5}$, apresentou em sua pauta as primeiras demandas por uma educação escolar quilombola, calcada na pedagogia dos seus territórios. Mas foi a partir da gestão do governo Presidente Luiz Inácio Lula da Silva, que houve uma intensificação dessas

\footnotetext{
${ }^{4}$ Conceitos utilizados pelo autor em artigo publicado na Revista Eletrônica Carta Maior do dia 25/10/16.

${ }^{5} \mathrm{O}$ I Encontro Nacional das Comunidades Negras Rurais Quilombolas foi realizado durante a Marcha zumbi dos Palmares de 17 a 20 de novembro em Brasília-DF onde foi criada a Comissão Nacional Provisória das Comunidades Rurais Negras Quilombolas.
} 
políticas sociais, com a criação de inúmeros programas e ações que visavam/visam contemplar as comunidades quilombolas.

Deve-se enfatizar, assim, que a Educação Escolar Quilombola possui uma ancoragem legal: a Lei Federal no. 10639/2003, cuja orientação consiste em que a Educação Básica adote nos conteúdos programáticos o estudo da história e da cultura afro-brasileira; a Convenção 169 da OIT (Organização Internacional do Trabalho), promulgada pelo decreto 5.051, de 2004, que garante o direito a uma educação apropriada às diferenças das populações étnicas; o Plano Nacional de Desenvolvimento de Populações Tradicionais (decreto 6.040, 2007), que aponta para a necessidade de se produzir modalidades de educação adequadas aos modos de vida das populações tradicionais; e a Resolução no 7 de 2010 do CNE (Conselho Nacional de Educação), que avança na garantia de uma educação diferenciada ao mencionar a necessidade de respeito por parte das escolas que atendem às populações do campo, comunidades indígenas e quilombolas, para com suas peculiaridades e modos de vida. Além disso, esta mesma resolução recomenda a utilização de pedagogias condizentes com as suas formas próprias de produzir conhecimentos.

Após as repercussões da Conferência Nacional de Educação (CONAE) de 2010, cujas discussões se deram em torno da necessidade de formulação de políticas educacionais para atender às especificidades das comunidades quilombolas, no dia 13 de julho de 2010, a Câmara de Educação Básica do CNE publicou a resolução no 4/201041, definindo Diretrizes Curriculares Nacionais Gerais para a Educação Básica. A Resolução institucionaliza a Educação Escolar Quilombola como modalidade de educação, cuja definição é a seguinte:

\begin{abstract}
Art. 41. A Educação Escolar Quilombola é desenvolvida em unidades educacionais inscritas em suas terras e cultura, requerendo pedagogia própria em respeito à especificidade étnico-cultural de cada comunidade e formação específica de seu quadro docente, observados os princípios constitucionais, a base nacional comum e os princípios que orientam a Educação Básica brasileira. Parágrafo único. Na estruturação e no funcionamento das escolas quilombolas, bem como nas demais, deve ser reconhecida e valorizada a diversidade cultural (Seção VII, Resolução no 4, CEB/CNE, 2010).
\end{abstract}

No ano de 2011, outros importante documentos produzidos foram os textos do Plano Nacional de Desenvolvimento da Educação (PNDE) 2011-2020 (que visa a implementar políticas específicas para a formação de professores para as comunidades quilombolas; expandir as matrículas de Ensino Médio destas; e ampliar a Educação Escolar Quilombola por meio de uma visão articulada ao desenvolvimento sustentável e à preservação da identidade cultural) e, por fim, as Diretrizes Curriculares Nacionais para a Educação 
Escolar Quilombola (BRASIL, 2012), aprovadas e anunciadas pela presidenta Dilma Rousseff, no dia 21 de novembro de 2012, em cerimônia no Palácio do Planalto, em alusão ao dia Nacional de Zumbi e da Consciência Negra. Esta última traz em seu texto a seguinte recomendação quanto à organização do ensino ministrado nas instituições educacionais inscritas em suas terras e/ou que atendam estudantes quilombolas:

[...] fundamentar-se, informar-se e alimentar-se: a) da memória coletiva; b) das línguas reminiscentes; c) dos marcos civilizatórios; d) das práticas culturais; e) das tecnologias e formas de produção do trabalho; f) dos acervos e repertórios orais; g) dos festejos, usos, tradições e demais elementos que conformam o patrimônio cultural das comunidades quilombolas de todo o país; h) da territorialidade. (BRASIL, 2012, p. 3) [Desta forma, objetiva:] I - orientar os sistemas de ensino e as escolas de Educação Básica da União, dos Estados, do Distrito Federal e dos Municípios na elaboração, desenvolvimento e avaliação de seus projetos educativos; II - orientar os processos de construção de instrumentos normativos dos sistemas de ensino visando garantir a Educação Escolar Quilombola nas diferentes etapas e modalidades, da Educação Básica, sendo respeitadas as suas especificidades; III assegurar que as escolas quilombolas e as escolas que atendem estudantes oriundos dos territórios quilombolas considerem as práticas socioculturais, políticas e econômicas das comunidades quilombolas, bem como os seus processos próprios de ensino-aprendizagem e as suas formas de produção e de conhecimento tecnológico; IV - assegurar que 0 modelo de organização e gestão das escolas quilombolas e das escolas que atendem estudantes oriundos desses territórios considerem o direito de consulta e a participação da comunidade e suas lideranças, conforme o disposto na Convenção 169 da OIT; V - fortalecer o regime de colaboração entre os sistemas de ensino da União, dos Estados, do Distrito Federal e dos Municípios na oferta da Educação Escolar Quilombola; VI -zelar pela garantia do direito à Educação Escolar Quilombola às comunidades quilombolas rurais $\mathrm{e}$ urbanas, respeitando a história, o território, a memória, a ancestralidade e os conhecimentos tradicionais; VII - subsidiar a abordagem da temática quilombola em todas as etapas da Educação Básica, pública e privada, compreendida como parte integrante da cultura e do patrimônio afro-brasileiro, cujo conhecimento é imprescindível para a compreensão da história, da cultura e da realidade brasileira. (BRASIL, 2012, p. 4).

Assim, podemos afirmar que as Diretrizes tem a função de orientar os sistemas de ensino para que eles possam implementar a Educação Escolar Quilombola, mantendo um diálogo com a realidade sociocultural e política das comunidades e dos movimentos quilombolas. 
Deste contexto de formulação da política de educação escolar quilombola, que hoje se encontra sob a coordenação da Secretaria de Políticas de Promoção da Igualdade Racial (SEPPIR), é importante ressaltarmos que elas se desdobram em duas importantes esferas de atuação que, ao menos em tese, deveriam se complementar: As políticas de financiamento voltadas para a atenuação das desigualdades físicas e estruturais, relacionadas à distribuição de recursos financeiros para as escolas situadas em comunidades quilombolas e legislações específicas que subsidiam ações para uma escola diferenciada, que dialogue com as especificidades dos territórios tradicionais das comunidades remanescentes de quilombo, contrapondo a hegemonia da forma escolar dominante (ARRUTI, 2009; CANÁRIO, 2006).

Ao discutir sobre as políticas de terra e educação para quilombos, Arruti (2011) chama atenção para o trânsito entre estas duas formas de se pensar a educação escolar quilombola, tal como foi pensada a própria política: aquela que busca ampliar e melhorar as condições da rede de educação nestas comunidades; e, aquela que tende a falar em uma educação pensada a partir e para as especificidades socioculturais desta população. Uma educação diferenciada, a exemplo da Educação Indígena e da Educação do Campo (ARRUTI, 2011, p. 292). Neste sentido, o autor adverte-nos que estar classificada no Censo escolar como escola localizada em áreas identificadas como de comunidades remanescentes de quilombo, beneficiando-se da política de educação escolar quilombola existente, não implica necessariamente na existência de qualquer diferenciação em sua forma física, processos pedagógicos, gestão, composição e formação dos professores ou nos materiais didáticos utilizados. Arruti (2011) afirma ainda que:

A classificação é atribuída no momento do preenchimento de formulário pelo diretor/a da escola, o que nos coloca o problema desta classificação não se dar nem por autoatribuição da comunidade, nem pelo reconhecimento prévio e oficial desta comunidade e seu território pelo Estado brasileiro. Temos exemplos interessantes de como isso produz variações importantes no cômputo geral, seja pela simples negação de que a escola seja quilombola, mesmo quando se trata de comunidade de notoriedade nacional, como acontece na llha da Marambaia (RJ), seja, ao contrário, quando tal classificação da escola ocorre sem ela encontre correspondência em uma comunidade quilombola. (ARRUTI, 2011, p. 293)

Tais considerações nos interpelam a pensar até que ponto as políticas de reconhecimento das diferenças têm, de fato, contemplado as diferenças, ou se não representam mais uma tentativa assimilacionista da cultura das minorias étnicas à cultura hegemônica, dita universal e dominante. Leva-nos a questionar, no plano prático, que tipo de relações tem firmado com aquilo que orienta as suas diretrizes: 
Uma proposta de educação quilombola necessita fazer parte da construção de um currículo escolar aberto, flexível e de caráter interdisciplinar, elaborado de modo a articular 0 conhecimento escolar e os conhecimentos construídos pelas comunidades quilombolas. Isso significa que o próprio projeto político- -pedagógico da instituição escolar ou das organizações educacionais deve considerar as especificidades históricas, culturais, sociais, políticas, econômicas e identitárias das comunidades quilombolas, o que implica numa gestão democrática da escola que envolve a participação das comunidades escolares, sociais e quilombolas e suas lideranças. (BRASIL, 2012, P.26)

Ainda na esteira dessas reflexões, considerando todos os aspectos trazidos até aqui, não podemos perder de vistas algumas ponderações sob o risco de sustentarmos um discurso ingênuo e superficial acerca da formulação e atuação dessas políticas. A primeira é a afirmação feita por Maroun (2013) quanto à relação das diretrizes e das demais ações com as realidades locais serem complexas e pouco lineares, embora consideremos também o quão recente são estas políticas. Como afirma a autora os textos das políticas já são, por si mesmo, resultado de disputas que, muitas vezes, expressam posições concretas e experiências locais (MAINARDES, 2006 apud MAROUN, 2013). Nesse caso, "depois de definidos os textos das políticas, a aplicação destas estará submetida a reinterpretações e novas disputas, que poderão vir a refletir outros embates locais" (MAROUN, 2013, p. 82).

A segunda é que as políticas de reconhecimento das diferenças emergem de um processo desencadeado por questões que tendem a desafiar o chão da escola. Neste sentido, encontram enfrentamentos e resistências não apenas burocráticas, bem como ideológicas. São caracterizadas por pressões e conflitos, se modificam, são reinterpretadas, têm contradições, logo podem gerar resultados diferentes do esperado (MAINARDES, 2006). Ainda de acordo com o pensamento de Mainardes (2006), entendemos que as políticas públicas voltadas para as comunidades quilombolas são marcadas pela presença do ordenamento do Estado, o que leva as comunidades a terem que se adequar e a apreender as categorias que estão em jogo. Entretanto, é interessante pensarmos, sobretudo, dentro do nosso contexto de análise, que as políticas não são apenas o que está previsto na lei, as políticas são também todas essas dinâmicas, jogo de forças, interpretações feitas pelo local, pelo modo como as populações tradicionais lidam com elas.

Um adendo importante a trazer é que antes mesmo da implementação de políticas governamentais e da legislação específica, já havia ações em comunidades quilombolas direcionadas a experimentar uma nova proposta de educação escolar culturalmente referenciada e/ou diferenciada. Um exemplo dessas ações é o Projeto "Educando com Arte: vivência de saberes" (2008), 
Quilombo Campinho Da Independência, Paraty (Rj):

território étnico e a luta por uma educação diferenciada

elaborado pelo quilombo Campinho da Independência com vistas a ser desenvolvido na escola local, tendo como base a cultura, as tradições e a memória coletiva da comunidade (SANTOS, 2008). Discorreremos sobre tal experiência no capítulo seguinte.

\section{O movimento de luta por uma educação diferenciada no Quilombo Campinho da Independência}

A luta do Quilombo do Campinho por uma educação diferenciada não se encontra à parte da luta pelo território, estas questões estão diretamente interligadas. A cosmovisão da comunidade compreende que esses dois espaços se relacionam o tempo todo. Nesse sentido, apresentam outras referências epistemológicas e organizações do pensamento. É a partir da perspectiva do território que se percebem enquanto grupos formadores deste; identificam as apropriações desiguais no/do território das quais emergem conflitos e injustiças invisibilizadas pelas relações de poder. A escola como uma instituição construída e perpetuada nessa lógica de relações desiguais de poder, tem sua importância, por isso, defender uma escola que esteja atrelada às lutas políticas das comunidades quilombolas, cujo projeto educacional reafirme a importância do território é essencial.

O debate sobre uma educação escolar quilombola no Quilombo do Campinho, bem como a construção de um projeto de educação baseada na cultura quilombola, com especificidades de seu território, teve como marco fundamental a implantação do Ponto de Cultura ${ }^{6}$ Manoel Martins em 2003, que recebeu este nome devido ao Griô que nasceu e viveu por muitos anos no Campinho da Independência.

O Ponto de Cultura desenvolveu um novo parâmetro de organização no Campinho abrindo o debate sobre uma educação diferenciada no território quilombola. Essa iniciativa contribuiu para a chegada de novos projetos e programas que trouxeram conquistas cotidianas importantes para a comunidade, tais como o reavivamento de práticas de plantio, de trabalhos artesanais, sobretudo, do jongo ${ }^{7}$ enquanto elementos de pertencimento identitário. Além disso, permitiram a construção de uma autogestão do seu território, de sua produção e do seu próprio trabalho (MAROUN \& CARVALHO, 2017). Todo este processo de formação identitária contribuiu para a

\footnotetext{
${ }^{6}$ Pontos de Cultura é uma ação do Programa Cultura Viva, do Ministério da Cultura (MinC), que, desde 2005, atua em parceria com os governos do estado, apoiando iniciativas culturais bem-sucedidas da sociedade civil.

${ }^{7} \mathrm{O}$ jongo, ou caxambu é um ritmo que teve suas origens na região africana do Congo-Angola. Chegou ao Brasil-Colônia com os negros de origem bantu trazidos como escravos para o trabalho forçado nas fazendas de café do Vale do Rio Paraíba, no interior dos estados do Rio de Janeiro, Minas Gerais e São Paulo.
} 
desnaturalização da hierarquização racial impregnada no imaginário social e nas relações sociais estabelecidas, sobretudo, introjetada pelos próprios quilombolas que vivenciam os efeitos perversos desse racismo, inclusive no espaço escolar. Emerge assim, deste contexto de formação que se inicia na comunidade, uma contradição: as crianças apresentavam interesses, rendimentos e desenvolturas distintas nas atividades desenvolvidas pelo Ponto de Cultura e na Escola. Enquanto no Ponto de Cultura elas viviam todo aquele momento de efervescência participando das oficinas, na escola elas apresentavam total desinteresse pelas atividades propostas. De acordo com o relato de uma liderança sobre as reuniões de pais, "(...) a sensação que eu tinha é que estavam falando de crianças diferentes, nem pareciam as mesmas que estavam aqui mergulhadas nas atividades das oficinas [organizadas pelo Ponto de Cultura]". (Laura, julho de 2013). Diante dessa problemática e visando acabar com a lacuna escola-quilombo, o Ponto de Cultura foi mobilizado para desenvolver projetos pedagógicos condizentes com as especificidades da comunidade quilombola. Uma das premissas dos projetos era, por exemplo, tornar os conteúdos escolares mais significativos para os alunos através da utilização de conhecimentos do local nas oficinas.

Foi em busca desse olhar sobre a educação escolar que a quilombola Laura dos Santos escreveu, com o apoio de uma pedagoga parceira da comunidade, o Projeto Educando com Arte $^{8}$ que foi aplicado na escola local. De 2005 até aproximadamente início de 2010 houve uma série de atividades que tinham como cerne "uma pedagogia quilombola" que visava à articulação dos saberes escolares com os não escolares. Uma forma de inserir a cultura quilombola na escola. Desenvolvidas com base na cultura, nas tradições e na memória coletiva da comunidade, as oficinas ${ }^{9}$, no âmbito escolar trouxeram elementos da vida cotidiana das crianças e jovens quilombolas para dentro do currículo.

Antes de adentrarmos na experiência do Projeto Educando com Artes é importante ressaltarmos a centralidade dos mediadores políticos neste processo de resistência, mas, também, de re-existência na luta por uma educação escolar quilombola. Como podemos perceber o Ponto de Cultura, compreendido aqui como um mediador político, atrelado às múltiplas e diferenciadas possibilidades de práticas educativas foi um "divisor de águas" na história da comunidade no sentido de desenvolver um novo parâmetro de organização no Campinho, sobretudo, de significar um marco fundamental que veio legitimar o debate sobre uma educação diferenciada na comunidade. Nesta mesma direção, consideramos significativo enfatizar a importância do

\footnotetext{
${ }^{8}$ O Projeto Educando com Arte foi sistematizado e publicado em livro com o apoio da Unesco no ano de 2008 (ver SANTOS, 2008).

${ }^{9}$ As oficinas realizadas eram: capoeira de angola, jongo, cerâmica artística, percussão, construção de tambores e cestaria
} 
protagonismo exercido pela liderança quilombola Laura dos Santos neste processo de mediação política. Laura que sempre foi uma educadora popular, contribuiu para o reavivamento dos processos educativos de formação identitária, da autoestima, da valorização e resgate da cultura negra na comunidade. Por conseguinte, destacamos também a importância do seu protagonismo frente à luta nacional de articulação das comunidades negras $\mathrm{e}$ rurais e ao Movimento de Fórum das Populações Tradicionais de Paraty no que diz respeito à formulação e implementação de políticas educacionais específicas para esses grupos. Laura participou como interlocutora das comunidades de todo o processo de elaboração das Diretrizes Curriculares Nacionais para a Educação Escolar Quilombola (2012). Dessa forma, falar do Educando com Artes é também falar da importância de sua luta frente ao debate sobre as questões educacionais dentro e fora da comunidade.

O Educando com Artes foi pensado em um momento onde a relação da escola com a comunidade já havia sido estremecida. Houve uma forte resistência na implantação do projeto na escola, o que levou as lideranças do Campinho a solicitarem a autorização diretamente à Secretaria Municipal de Educação de Paraty-RJ para implementação do mesmo. O pedido então foi aceito e dessa forma o Educando com Artes foi incorporado à escola. Através de reuniões sistematizadas, escola e comunidade organizaram e planejaram todos os eixos e temas abordados nas oficinas. Ao fim as ações foram articuladas aos conteúdos programáticos da escola.

A incorporação do projeto na escola não se deu de forma aberta, receptiva e dialógica, mas com pressão exercida pela própria comunidade, que agora tinha em mãos uma declaração da SME. Com o passar do tempo, o projeto foi questionando a lógica de hierarquização presente no sistema escolar e propôs na sua metodologia colocar toda a comunidade escolar (professores, alunos e demais funcionários) numa posição horizontal aos Griôs ${ }^{10}$, artesãos, lideranças políticas e crianças quilombolas, mesmo que num contexto de grande resistência e luta por espaço de poder. Nesse contexto, não havia quem soubesse mais e quem soubesse menos, haviam saberes, conhecimentos diferentes. Laura lembra que a repercussão do projeto foi muito positiva em relação às crianças que moravam na comunidade. "[...] Um momento de fortalecimento, de autoestima, de orgulho de ser negro" (Laura, julho de 2013). Os estudantes passaram a se interessar pelas atividades, a participar expressivamente, a ter entusiasmo pelas tarefas, sentiam-se mais seguras para falar, para se expor diante da resolução de problemas. Tratava-se da difusão do conhecimento que tinha como base os saberes próprios da comunidade. Vejamos o que nos relata uma das lideranças:

\footnotetext{
${ }^{10}$ Os Griôs são os mais velhos das comunidades, considerados como fontes de saberes ancestrais. Podem ser descritos como contadores de histórias, que têm como missão a valorização da cultura local através da tradição oral.
} 
[...] A gente recebia muita reclamação. As crianças mal sabiam ler e escrever, diziam que não tinham interesse, que não aprendiam de jeito nenhum. $E$ nem iam aprender, não naquele formato de escola. A prática ela deixa a criança tão feliz, entende? Quando ela está fazendo alguma coisa que ela vê o sentido, ela compreende. Então quando você pede a ela para escrever sobre aquilo ela escreve, entendeu? Então a gente acha que a escola ela tem que valorizar a cultura, ela tem que reconhecer, entender, reconhecer e valorizar a cultura, porque a criança quando chega na escola os valores dela deveriam ser o mais importante, a escola deveria reconhecer isso, mas a escola é um outro mundo, eu digo que uma criança tipo a Lalá... (Lalá aparece onde estávamos e fica um bom tempo atenta, ouvindo a nossa entrevista) Lalá pula em árvore, corre, come fruta, vê passarinho, ela tem uma série de conhecimentos, agora quando ela chega dentro da escola... (Laura Maria dos Santos, Março de 2012).

A reflexão feita por Laura acerca do distanciamento da cultura da criança quilombola em detrimento da cultura privilegiada na escola nos remete ao que explicita Walsh (2011) ao trazer o contexto de luta dos povos afrodescendentes pelo reconhecimento dos seus direitos no campo da educação. Para a autora, esse reconhecimento é traduzido da seguinte forma:

É o valor de ensinar sobre o que muitos anos nos ensinaram que não teria valor, os conhecimentos que não haviam nos dito que eram conhecimentos, a luta é voltar a esta forma de conhecimento, a esta maneira de entender a vida, de entender nossos próprios saberes como também envolver os processos educativos nesta nossa visão de história e conhecimento. (GARCIA \& WALSH, 2004, p. 342 apud WALSH, 2011, p. 4).

Cerca de um ano depois da implementação do Educando com Artes, houve substituição na gestão da SME e o projeto foi retirado da escola por solicitação da própria direção escolar. Esta iniciativa foi tomada sem que ao menos fosse feito um comunicado à comunidade. O resultado foi então a pressão das lideranças por uma "escola quilombola". Migra-se de uma proposta inicial de pedagogia multicultural, na qual não haveria supremacia de uma cultura sobre a outra (CANDAU, 2008), para uma proposta pedagógica especificamente voltada para a questão quilombola (MAROUN, NORONHA \& CARVALHO, 2013). Nessa perspectiva, há um deslocamento da ideia de um Projeto Político Pedagógico da escola que venha a contemplar a comunidade, para a escola incorporada ao Projeto Político Comunitário. "[...] Acreditamos [a partir desse momento] que a escola quilombola deva ser construída por nós mesmos" (Laura Maria dos Santos, março de 2013), enfatizou uma das lideranças. 
Toda essa vivência da comunidade junto à escola local nos remete à discussão trazida por Arroyo (2012). Para o autor, grupos como as comunidades quilombolas, ao se afirmarem sujeitos de saberes próprios, de outros processos de aprendizagem, de formação, de conscientização política e cultural, passam a resistir a esse modelo educacional hegemônico predominante, sobre o qual a instituição escolar ainda está fundamentada. Isso ocorre justamente porque eles se afirmam por meio de suas diferenças. Nesse sentido, entendem que ao longo da história de formação da sociedade foram submetidos a relações desiguais de poder/saber/dominação; submetidos à destruição de seus modos de pensar e de pensarem-se. Além disso, por não terem suas culturas, identidades e memórias reconhecidas, não se reconhecem como produtores da história da produção intelectual e cultural. Assim, a articulação política das lideranças reflete o esforço dos povos excluídos para visualizar, construir e aplicar um projeto onde às aspirações e os critérios culturais próprios são o fundamento.

Sem dúvida, a experiência do projeto Educando com Artes no Quilombo do Campinho significou muito mais do que propor ações diferenciadas para serem realizadas na/pela escola. Como afirma Laura dos Santos: "o projeto nos possibilitou fazer um diagnóstico" (Laura Maria dos Santos, 2013). Neste segundo momento então, a AMOQC (Associação de Moradores do Quilombo Campinho) passa a compreender que uma "escola quilombola" se fundamenta em um processo de construção coletiva, algo que seja pensado pela própria comunidade, ainda que em parceria com a escola. Tal perspectiva de educação e de escola aponta para, dentre outras coisas, a contemplação e legitimação tanto dos seus saberes tradicionais, como de suas pedagogias próprias. Trata-se de uma concepção que nos remete ao que Walsh (2014) chama de pedagogia decolonial, capaz de acionar práticas, metodologias, estratégias e maneiras de fazer que se entrelaçam e são construídas em resistência à colonialidade expressa na hegemonia da lógica epistêmica ocidental. Que opera na insurgência, na afirmação, na re-existência, na rebeldia, na ruptura ao imaginar e buscar construir um mundo diferente.

Um primeiro ponto desta proposta de "escola quilombola" remete à articulação dos ambientes educativos formais e não formais: a própria escola deveria compreender e trabalhar com a ideia de que a educação acontece não apenas no seu interior, mas também fora dos seus muros. Nessa concepção, os espaços localizados nas dependências da comunidade, tais como o jongo, as contações de histórias com os Griôs, a casa de farinha, o viveiro de mudas da Juçara, o campo de futebol, a casa de artesanato e tantos outros, passam a serem considerados importantes espaços de aprendizagem, que deveriam ser apropriados pela a escola. Quanto à importância atrelada a esses espaços de vivências comuns, Arroyo (2012, p. 85-86) diz que estes são o que dão "força formadora aos símbolos". É o que faz pensar, produzir identidades, valores, leituras e interpretações de mundo e de si mesmo como coletividade. Portanto, 
não se trata apenas de destacar o "caráter didático desses rituais e símbolos", pois isso não daria conta de suas virtualidades formadoras. São mais do que didáticas. A sua força está em "fazer presente a força pedagógica do real", por isso a necessidade dessa virtualidade formadora da vida produtiva chegar à escola formal e não apenas nos espaços informais de educação.

Outro ponto relevante na fala das lideranças é o engessamento da escola tradicional no que se refere, dentre outras coisas, aos horários inflexíveis, aos calendários e às metodologias aplicadas. Reivindicam a necessidade de um olhar diferenciado para o contexto no qual a escola está inserida no momento em que se constrói o planejamento escolar:

[...] As escolas urbanas têm de ser diferentes porque as questões urbanas são específicas daquele local. As escolas rurais têm que ser diferenciadas porque elas têm questões específicas, rurais, o seu tempo é diferente da área urbana que não precisa ter um tempo do plantio. A escola quilombola, além de ter a questão rural tem a questão da etnia, da tradicionalidade, que precisa ser respeitada. Isso tem que ser levado para dentro da escola, e é por isso que afirmo com tanta veracidade que é a cultura quem forma, a cultura é esse preenchimento, a cultura centra o ser humano, ela organiza a cabeça do ser humano. E quando a escola compreende o seu verdadeiro papel e função dentro de uma sociedade específica, ela passa a valorizar o contexto do aluno, os seus saberes e costumes. (Laura Maria dos Santos, outubro de 2014)

Ao trazerem à tona todas essas questões, as lideranças do Campinho enfatizam que a escola precisa ser "ressignificada". Segundo Brandão (1984), a leitura da realidade local proporcionada por este novo formato de escola seria feita com as categorias de que dispõem os próprios sujeitos, que pertencem ao seu universo. Esta mesma ideia é expressa por Candau (2000) quando afirma a necessidade de "reinventar a escola". Esse é um debate que não deve ocorrer apenas dentro da escola, mas nos espaços de discussão da comunidade:

Tudo o que vem de cima para baixo é complicado, há um problema de sistema. É complicado discutir essas questões na escola. Tem de ser à base de enfrentamento mesmo, não tem jeito. A escola manipula e de que forma a gente garante um mínimo de discussão que não seja manipulada? É aqui neste espaço. É entre nós. (Laura Maria dos Santos, março de 2015)

A tomada de posição política explicitada na fala das lideranças do Campinho remete ao que afirma Walsh (2012) sobre as lutas, avanços e desafios recentes e atuais que visam "interculturalizar" e "decolonizar" as estruturas e às instituições do Estado. É importante ressaltarmos que, ao criticarem os saberes legitimados pela escola, as suas práticas 
descontextualizadas da realidade local, o racismo ainda presente no contexto escolar, as incipientes políticas públicas que reconheçam, reparem e garantam o direito das comunidades a uma educação voltada para suas especificidades, as lideranças visibilizam o desrespeito aos processos sociais, econômicos, políticos, culturais em que formam e são formados na/pela comunidade. Nesse caso, trazem consigo todo pensamento social, pedagógico enraizado nas relações políticas, nas experiências sociais em que este é produzido. Como afirma Arroyo (2012, p. 10), trata-se de "outros sujeitos, que trazem consigo outras pedagogias de sua formação" e são essas pedagogias que passam a interrogar a escola, tal como observamos nos relatos apresentados.

Outra questão que gerou recusa da comunidade por esse modelo educacional hegemônico ou por qualquer tentativa de diálogo com a escola local (nesse segundo momento) pode ser explicada, também, pela forma como a SME de Paraty concebe a Escola Municipal localizada em um território diferenciado ${ }^{11}$. Embora dentro de um território quilombola a mesma se encontra subordinada à coordenação da Educação Rural de Paraty, que, por sua vez, à época dos debates e conflitos, não trazia em seu projeto político pedagógico aplicado de forma única em todas as escolas inseridas no contexto rural - as questões históricas, políticas, sociais e culturais da população afro brasileira, tão pouco as especificidades dos remanescentes de quilombo. Em Paraty não havia nenhuma atenção diferenciada para as escolas em territórios quilombolas, o que trazia sérios desafios para a comunidade Campinho da Independência à implementação de uma educação escolar quilombola. Por outro lado, toda essa experiência vivida pela comunidade em sua relação com a escola e com a SME provocou nas lideranças um novo posicionamento crítico e político. Na concepção de Laura dos Santos:

Eu não acredito numa escola que o governo implante e dê o nome de escola quilombola. Não acredito nisso. Eu creio que a escola que nós queremos é a que reconheça nossos valores tal como somos. Apesar dos avanços na educação do quilombo, ainda estamos num campo de luta muito grande, porque primeiro a escola tem que estar na cabeça de cada um. Eu já ouvi falar de experiências, nas quais se conseguiram e depois se desfizeram. Então, penso que a concepção de escola deva estar em nós para que não se acabe. Essa concepção de escola tem que estar dentro da gente, porque senão ela se acaba. Ou seja, ela tem que ser construída mesmo, passo a passo. Devemos enxergar essa construção como uma luta da sociedade e não como benefício do governo. (Laura Maria dos Santos, março de 2013).

\footnotetext{
${ }^{11}$ De acordo com as Diretrizes Curriculares Nacionais para a Educação Escolar Quilombola (BRASIL, 2012), o termo escola quilombola contempla tanto as escolas que se localizam em territórios quilombolas, como as escolas que atendem alunos oriundos de tais comunidades.
} 
O relato acima explicita o quanto a experiência de educação escolar quilombola denota uma epistemologia que é de resistência e que pode ser entendida como "uma maneira de enfrentar a colonialidade do poder, do ser e também do saber dominantes" (WALSH, 2011, p. 5).

A experiência vivenciada pelo quilombo do Campinho, em um primeiro momento, na relação entre escola-comunidade, e, no que concerne à luta por uma escola com perspectivas quilombolas, apresenta dilemas e opções singulares para a reflexão acerca de como essa modalidade de educação tem sido pensada e construída pelos próprios quilombolas. Isso antes mesmo da publicação dos respectivos textos legais. Outra questão de extrema importância que emerge nesse contexto é a reflexão sobre a forma como políticas educacionais específicas têm sido pensadas e elaboradas e, em que medida, podemos perceber diálogos, embates e/ou aproximações destas com as experiências pontuais vivenciadas pelas próprias comunidades. Acreditamos que, somente a partir de um olhar mais analítico sobre essas problemáticas e experiências poderemos ter uma compreensão mais ampla dos principais avanços, limites e lacunas presentes nos textos legais, sobretudo, na implementação dessas políticas no âmbito das escolas situadas em áreas quilombolas e/ou que atendam alunos quilombolas.

As comunidades tradicionais têm avançado na questão da mobilização e dos processos próprios de mediação na luta por uma educação diferenciada que reconheça a epistemologia dos seus saberes próprios e do seu território étnico. Portanto, é com base nessa constatação que conferimos a importância dos mediadores políticos no âmbito das lutas vivenciadas pelas comunidades quilombolas, tal como percebemos a centralidade de Laura dos Santos, liderança da comunidade responsável pela pauta da educação no Quilombo do Campinho. Tal tomada de posição política das lideranças comunitárias reflete o esforço dos povos excluídos para visualizar, construir e aplicar um projeto onde as aspirações e os seus critérios culturais próprios são o fundamento educativo (CASTRO-GÓMEZ, 2005). Algo que seja pensado de/desde os sujeitos e não apenas para os sujeitos (WALSH, 2012).

A educação escolar quilombola é uma categoria recente, ainda em desenvolvimento e em disputa pelos principais atores sociais envolvidos, o que pressupõe que a elaboração de políticas específicas para esta modalidade de educação representa um aprendizado em processo tanto para os quilombolas, quanto para os gestores e professores (MAROUN, CARVALHO, 2016). Com tudo isso, não podemos perder de vistas que apesar de toda complexidade observada, tais políticas imprimem grande importância no âmbito da luta por uma educação escolar quilombola pleiteada pelas comunidades. Importância que se dá, sobretudo, no âmbito do empoderamento dos próprios sujeitos e/ou grupos sociais que tiveram suas identidades invisibilizadas histórica e socialmente e agora passam a interrogar a escola e a se afirmar enquanto sujeitos de direitos. 
Em linhas gerais, compreendemos que é pelo viés da resistência a uma escola branca, monocultural e homogeneizante que a luta por uma escola quilombola no Campinho da Independência ganha corpo e se sustenta, abrindo caminhos e inaugurando outras possibilidades neste histórico de relação entre escola-comunidade, ao protagonizar uma experiência Outra de construção de educação e de escola no presente momento.

No próximo tópico apresentaremos o novo momento da luta por uma educação diferenciada no Quilombo do Campinho. Trataremos do processo de reorientação curricular realizado na escola Municipal Campinho da Independência, inserida nessa comunidade.

\section{Construindo caminhos para uma educação diferenciada quilombola}

Por força da luta das lideranças do quilombo do Campinho, a partir do convênio de cooperação interinstitucional entre Instituto de Educação de Angra dos Reis (IEAR-UFF) e a SME de Paraty-RJ, foi implantado em 2017 o programa de formação continuada para professores/as atuando em escolas quilombolas de Paraty e o projeto de construção de uma educação diferenciada via pedagogia de projetos e temas geradores. Assim, encontra-se em andamento 0 processo de reorientação curricular para o primeiro segmento escolar (turmas de pré e de $1^{\circ}$ ao $5^{\circ}$ ano) da Escola Municipal Campinho da Independência.

Tendo como referência o contexto de embates políticos e reivindicações das comunidades, foram planejadas três etapas principais para a construção e implementação de um "currículo quilombola": 1) "Etapa de sensibilização de professores e comunidade"; 2) a etapa de "Estudo das Leis, Diretrizes e Bases da Educação Escolar Quilombola" e a "Pesquisa e Elaboração de Diagnóstico Sociocultural"; 3) "Construção do Plano Político Pedagógico e Reorientação curricular das Escolas".

$\mathrm{Na}$ primeira etapa, "Etapa de sensibilização de professores e comunidade", as atividades tiveram um caráter lúdico e reflexivo. Buscou-se, principalmente, envolver a comunidade escolar - professores, gestores, funcionários, pais e mães - no e com o projeto. Nesse sentido, o significado de sensibilizar aqui envolveu tanto demonstrar a relevância de um currículo diferenciado e da educação escolar quilombola para a comunidade, quanto tocar professores, funcionários e mães/pais para o cotidiano dos territórios quilombolas como princípio e mobilizador educativo. É importante ressaltar que a comunidade quilombola (pais, mães e lideranças) participou diretamente dos encontros de formação, o que nos ajudou a meditar sobre articulações que poderiam ser feitas entre o cotidiano e a construção do currículo. As lideranças também trouxeram para 0 debate as experiências educativas aplicadas 
previamente na comunidade, principalmente o Educando com Arte mencionado acima. Do mesmo modo, nos permitiu observar a dimensão política da escola mediante as reivindicações da própria comunidade por uma educação articulada com seu contexto e necessidades.

Os encontros da Primeira Etapa se desdobraram em três oficinas: i) "Memórias e processo de escolarização"; ii) "Diferença, racismo e práticas Pedagógicas"; iii) e "História e cultura afro-brasileira". O objetivo da primeira oficina foi realizar uma reflexão coletiva sobre a importância e a influência da instituição escola em nossas vidas. Os participantes foram estimulados a produzir e compartilhar suas narrativas sobre trajetória escolar. A partir dessas narrativas, debatemos a importância política da escola em um território quilombola e, consequentemente, a necessidade de a agenciarmos para cumprir os anseios da comunidade por uma educação diferenciada. Concluiuse que a escola como um espaço de subjetivação pode ser um instrumento importante na luta pela defesa dos territórios quilombolas, sobretudo, à medida que assume pedagogias que questionam constantemente as formas de subalternização, desumanização, opressão e os padrões de poder que invisibilizam as diferentes formas de saber e de ser (MARCONDES, 2017; CARVALHO, 2014).

$\mathrm{Na}$ oficina "Diferença, racismo e práticas pedagógicas" foram abordadas as problemáticas da diferença e do racismo no espaço escolar, bem como, as probabilidades de mobilização dessas questões nos processos pedagógicos. 0 objetivo foi refletir sobre a necessidade de se pensar a identidade cultural como um condicionante dos processos educativos. Assim, pensar a identidade, bem como, a diversidade e as diferenças é extremamente importante, pois, nos leva a pensar sobre as especificidades e necessidades dos sujeitos e grupos no processo de ensino-aprendizado. Como ficou explícito no debate, isso não é um processo simples, mas, marcado por conflitos e contradições - o que também deve ser incorporado como mobilizador pedagógico. A formação também permitiu a desconstrução de idealizações de uma identidade única acerca das comunidades quilombolas. Os quilombos no Brasil são heterogêneos e complexos, e para se pensar um currículo diferenciado é fundamental ponderar tanto sobre as especificidades quanto sobre a diversidade interna e externa dessas comunidades. Todas essas constatações reforçam a nossa tese de que pensar em experiências de educação escolar quilombola pressupõe nos abrirmos à pluralidade de possibilidades que estas representam (CARVALHO, 2014).

$\mathrm{Na}$ terceira oficina, o objetivo foi debater o sentido da "História e Cultura Afro-brasileira" e refletir sobre como essa cultura/história tem ressonância em nossa sociedade e na escola. Um dos princípios norteadores desse encontro foi a não existência de uma história e cultura afro-brasileiras únicas. A partir da construção coletiva de uma linha do tempo sobre fatos históricos protagonizados por afro-brasileiros, notou-se que a experiência negra-africana 
no Brasil e na Diáspora é bastante complexa. A história quilombola deve ser pensada como um dos elementos da história e cultura afro-brasileira, ainda que tenha que ser pensada as suas peculiaridades locais e regionais.

$\mathrm{Na}$ Segunda Etapa do projeto, as atividades se dividiram em dois âmbitos: nas oficinas de formação que envolveram o "Estudo das Leis, Diretrizes e Bases da Educação Escolar Quilombola"; e, a "Pesquisa e Elaboração de Diagnóstico Sociocultural" das escolas localizadas nos quilombolas do Campinho através da aplicação de questionários junto aos alunos e a realização da metodologia FOFA junto a comunidade escolar.

Referente ao "Estudo das Diretrizes curriculares Nacionais para uma Educação Escolar Quilombola", foram realizadas três oficinas com professores e comunidade: i) "Construindo a linha do tempo da comunidade"; ii) "Cartografia social da escola e do quilombo"; iii) e, "Leis e diretrizes para uma educação escolar quilombola". O objetivo foi produzir conteúdos pudessem auxiliar na compreensão das realidades quilombolas, bem como, criar instrumentos e parâmetros para a reorientação curricular da escola assentada nas Diretrizes.

Nas duas primeiras oficinas, buscou-se compreender e discutir a história e o território do quilombo do Campinho. No primeiro encontro foram realizadas reflexões sobre as ideias de tempo e história como construções humanas e instâncias passíveis de transformação e ressignificação. Nesse sentido, as histórias dos quilombos não estão prontas e acabadas, além disso, qualquer modificação subjetiva e política no presente altera a forma de se conceber e significar o passado dessas comunidades. Como produto dessa oficina, foram construídas linhas do tempo que articulavam a história do quilombo do Campinho às histórias municipal, estadual e nacional. $O$ objetivo foi demonstrar que a história da comunidade está ligada (afetando e sendo afetada) a outras escalas da produção histórica.

$\mathrm{Na}$ segunda oficina foi realizada uma atividade de cartografia social com professores e comunidade escolar. Tal oficina, primeiramente, buscou-se constatar os aspectos estruturais e simbólicos do território: os lugares importantes, os núcleos no interior da comunidade, os locais de trabalho e lazer, os caminhos, locais simbólicos etc.. Segundo, foi mapeado as localidades de residência dos alunos e a trajetória realizada por eles até as escolas. Os produtos dessas oficinas foram: a confecção de croquis dos territórios quilombolas e mapas com a localização da residência dos alunos.

$\mathrm{Na}$ terceira oficina, após a consolidação dos conhecimentos sobre a história e o território das comunidades, realizamos estudos sobre as leis e diretrizes que institucionalizam a educação escolar quilombola. $O$ foco foi dado às Diretrizes Nacionais da Educação Escolar Quilombolas (2012), no entanto, nas discussões pretendeu-se pensar o caráter conceitual e o caráter organizacional das várias leis e diretrizes a luz do contexto do Quilombo do Campinho. Os professores e comunidade foram incentivados a pensar como as 
diretrizes e leis poderiam ser mobilizados e aplicados em cada contexto, bem como, quais seriam os obstáculos e as formas de transpô-los.

Concomitante às oficinas, foi realizado o diagnóstico das comunidades. Foram aplicados nas turmas de pré ao quinto ano na Escola M. do Campinho da Independência o total de 90 questionários. Devido à restrição de espaço aqui não poderemos analisar os resultados da aplicação dos questionários, no entanto, a partir deles buscou-se compor o perfil do alunado na escola do Campinho e vislumbrar suas concepções sobre cultura quilombola, território, lazer e escolarização. Do mesmo modo, com a aplicação da metodologia FOFA junto a comunidade escolar, a fim de vislumbrar o imaginário e ideias sobre as "Fortalezas", "Oportunidades", "Fraquezas" e "Ameaças" em torno da organização e do currículo da escola. A dinâmica da metodologia FOFA nos apresentou os anseios, desejos e medos da comunidade sobre a escola, o que permitiu uma reflexão crítica sobre o passado e o presente, bem como, sobre um futuro possível para a escola. Ambos os processos - a aplicação de questionários e a realização da FOFA - geraram uma série de informações sobre a escola e a comunidade escolar que nos subsidiarão na próxima etapa para a reorientação curricular da escola.

\begin{tabular}{|c|c|c|}
\hline \multicolumn{3}{|c|}{ FORTALEZAS } \\
\hline $\begin{array}{c}\text { Professores } \\
\text { eficientes/atenciosos }\end{array}$ & $\begin{array}{l}\text { Espaço muito rico para } \\
\text { aproveitar }\end{array}$ & $\begin{array}{l}\text { Muitas famílias estão atentas a } \\
\text { educação em casa }\end{array}$ \\
\hline Comunidade escolar unida & $\begin{array}{l}\text { A história da cultura da } \\
\text { comunidade }\end{array}$ & Boa qualidade da merenda \\
\hline Artesanato & Aulas de reforço escolar & Futebol na comunidade \\
\hline Escola no território & Participação dos pais & $\begin{array}{c}\text { Confiança na relação mães/pais - } \\
\text { professores }\end{array}$ \\
\hline Restaurante do quilombo & $\begin{array}{c}\text { Luta da comunidade pela } \\
\text { escola }\end{array}$ & Resistência da comunidade \\
\hline \multicolumn{3}{|c|}{ FRAQUEZAS } \\
\hline Ausência de 20 Segmento & Baixos salários & $\begin{array}{c}\text { Não informação dos pais } \\
\text { sobre a sala de estudo } \\
\text { dirigida }\end{array}$ \\
\hline $\begin{array}{c}\text { Não aceitar orientações dos } \\
\text { professores }\end{array}$ & $\begin{array}{c}\text { Falta de discussão e } \\
\text { socialização do calendário } \\
\text { escolar }\end{array}$ & Falta do EJA na escola \\
\hline A rodovia & Evasão escolar no campinho & $\begin{array}{l}\text { Falta de equipe } \\
\text { multidisciplinar }\end{array}$ \\
\hline Falta de uma biblioteca & $\begin{array}{l}\text { Falta de mais inspetores de } \\
\text { alunos }\end{array}$ & \\
\hline
\end{tabular}

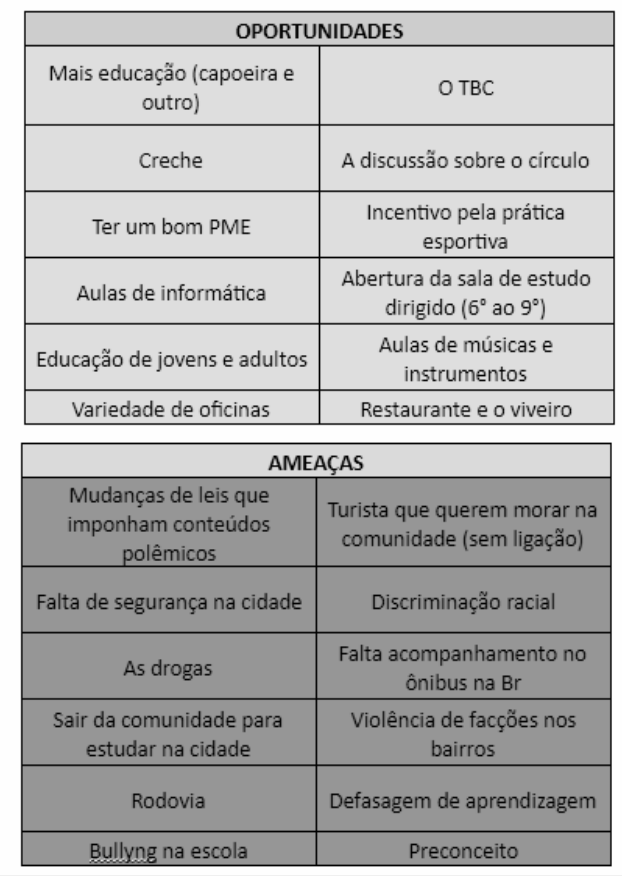

Resultados da FOFA realizada na Escola M. Campinho da Independência. 2017

Como se nota nos quadros, com a aplicação da metodologia FOFA podemos dimensionar a percepção da comunidade sobre os processos que envolvem mudanças curriculares e transformações na organização da escola. Unido aos dados gerados a partir da aplicação dos questionários, compõe um horizonte factível para a implementação de uma educação escolar quilombola 
que tenha significado para a comunidade. Trata-se de um projeto de educação que rompa com o distanciamento entre a cultura da criança quilombola e a cultura privilegiada no espaço escolar, o que remete ao que explicita Walsh (2011), ao trazer o contexto de luta dos povos afrodescendentes pelo reconhecimento dos seus direitos no campo da educação. Para a autora, esse reconhecimento pode ser traduzido da seguinte forma:

É o valor de ensinar sobre o que muitos anos nos ensinaram que não teria valor, os conhecimentos que não haviam nos dito que eram conhecimentos, a luta é voltar a esta forma de conhecimento, a esta maneira de entender a vida, de entender nossos próprios saberes como também envolver os processos educativos nesta nossa visão de história e conhecimento. (WALSH, 2011, p. 4).

\section{Considerações finais}

O presente artigo, para além do relato e descrição de uma luta protagonizada por quilombolas e um projeto curricular pautado nesse movimento, traz consigo questões importantes que se configuram como desafios no que tange a promoção, implementação e continuidade das políticas educacionais voltadas para o reconhecimento das diferenças étnicas e culturais. Além de subsidiar reflexões e inspirar outras lutas no campo educacional.

Não obstante, a experiência aqui investigada deriva de uma demanda comunitária acionada por uma política educacional específica, diferenciada e fragilizada em tempo tão algozes. Dessa forma, diante de um cenário político marcado pelo retrocesso de algumas dessas políticas, que vinham consolidando-se em governos anteriores, compreendemos que a experiência aqui trazida reflete processos de luta contra-hegemônica e decoloniais à medida que são protagonizadas de e a partir de sujeitos "Outros", que sofreram uma história de submissão e subalternização. Por conseguinte, ao mesmo tempo em que denuncia os processos que tangenciam as diferenças existentes no chão da escola, os mecanismos que reforçam as condições de subalternidades de determinados grupos, anuncia processos de transgressão e de desobediência epistêmica que vêm acontecendo nas brechas decoloniais, nas fissuras... (WALSH, 2016).

No que tange ao projeto de reorientação curricular para uma educação escolar quilombola no Campinho, este se encontra em processo. Um movimento de idas e vindas. De avanços e de estagnações frente às burocracias encontradas e algumas resistências que ainda se perduram. No entanto, já percebemos alguns frutos. Primeiro, a despeito dos conflitos vivenciados entre comunidade quilombola e escola. As atividades do projeto têm cada vez mais aproximado escola e comunidade. As tensões não se 
encerraram, contudo, foi estabelecida nas formações uma arena de troca e diálogo que tem beneficiado tanto os professores - ao assimilarem melhor a realidade política e cultural da comunidade, quanto as lideranças quilombolas ao compreenderem melhor o funcionamento, organização e legislações que ordenam a escola. Isso tem refletido na construção do currículo, que tem como orientação as demandas, necessidades e realidades do território quilombola.

O território, nesse contexto, aparece como uma via de mão dupla. Ao tempo que se mostra como o mediador dos processos educativos, uma vez que estabelece as referências para a construção dos processos educativos na escola, também é reativado e revigorado, principalmente no imaginário e prática dos alunos, como uma instância fundamental para a reprodução das suas vidas. Em outros termos, sendo o quilombo significado e positivado na escola, a comunidade passa a valorizar e defender com mais afinco e propriedade o território.

No momento atual, o projeto se encontra em sua terceira etapa, o que envolve a revisão do Plano Político e Pedagógico (PPP) das escolas e a construção da rede temática que regerá os projetos pedagógicos - via matrizes temáticas e planos de aula. Ainda há muito a se fazer, contudo, já vislumbramos uma educação escolar com perspectivas quilombola, a partir da tríade terra-território-cultura, vivenciadas no chão da escola.

\section{Referências Bibliográficas}

ANJOS, R. S. A. Quilombos: geografia africana-cartografia étnica - territórios tradicionais. Brasília: Mapas, 2009.

Territorialidade quilombola: fotos \& mapas. Brasília: Mapas, 2011.

ARROYO, Miguel G. Outros sujeitos, outra pedagogias. Petrópolis, RJ: Vozes, 2012.

ARRUTI, José Maurício; MAROUN, Kalyla e CARVALHO, Ediléia. Educação quilombola em debate: A escola em Campinho da Independência (RJ) e a proposta de uma Pedagogia Quilombola.In: CUNHA, Ana Stela de Almeida (Org). Construindo Quilombos, desconstruindo mitos: a Educação Formal e a realidade quilombola no Brasil. São Luís: SETAGRAF, 2011, p. 29- 43.

ARRUTI, José Maurício. "Políticas Públicas para quilombos: Terra, Saúde e Educação" In: Marilene de Paula e Rosana Heringer. (Org.). Caminhos Convergentes - Estado e Sociedade na Superação das desigualdades Raciais no Brasil, Rio de Janeiro: Fundação HenrichBoll, ActionAid, v. 1, p. 75-110. 2009.

BRANDÃO, Carlos Rodrigues. Educação Popular. São Paulo: Brasiliense, 1984. 
Quilombo Campinho Da Independência, Paraty (Rj):

território étnico e a luta por uma educação diferenciada

BRASIL. Diretrizes Curriculares Nacionais para a Educação Escola Quilombola. Brasília, DF: 2012.

CANÁRIO, R. A escola tem futuro: das promessas às incertezas. São Paulo: ARTMED, 2006.

CANDAU, Vera Maria (org.). Sociedade, educação e cultura (s): questões e propostas. 2. ed. Petrópolis, RJ: Vozes, 2008.

(Org.). Reinventar a escola. Rio de Janeiro: Vozes, 2000.

CARPENEDO, M. Quando a resistência se torna política pública. Analisando a produção de subjetividade(s) nas políticas públicas de equidade de gênero no campo do trabalho. $150 \mathrm{f}$. Dissertação (Mestrado em Psicologia Social) - Instituto de Psicologia, Universidade Federal do Rio Grande do Sul, Porto Alegre, 2011.

CARVALHO, Ediléia. "Tem que partir daqui, é da gente": a construção de uma escola "outra" no Quilombo Campinho da Independência, Paraty-RJ. Rio de Janeiro: Imperial Novo Milênio, 2016.

CASTRO-GÓMEZ. Santiago. La poscolonialidad explicada a los niños.

Bogotá: Editorial Universidad del Cauca; Instituto Pensar/Universidad Javeriana, 2005.

GOMES, Flávio dos Santos. Mocambos e Quilombos: Uma história do campesinato negro no Brasil -1 ed, - São Paulo: Claro Enigma, 2015

GUSMÃO, Neusa M. M. Campinho da Independência: um caso de proletarização Caiçara. São Paulo: PUC, 1979.

MAINARDES, Jeferson. Abordagem do ciclo das políticas: uma contribuição para a análise de políticas educacionais. Educação \& Sociedade. Campinas, SP, v. 27, n. 94, p. 47-69, 2006.

MAROUN, Kalyla. Jongo e educação: a construção de uma identidade quilombola a partir dos saberes étnico-culturais do corpo. Tese (Doutorado). Rio de Janeiro: Programa de Pós-Graduação em Educação. Pontifícia Universidade Católica do Rio de Janeiro - PUC/RIO, 2013.

MAROUN, Kalyla e CARVALHO, Ediléia. Experiências de Educação Quilombola: As relações entre escola e comunidade. Revista FAEEBA - Ed. e Contemp., Salvador, v. 26, n. 49, p. 87-102, maio/ago. 2017.

MAROUN, K., NORONHA, Suely, CARVALHO, Ediléia. Educação escolar quilombola: Diálogos e interfaces entre experiências locais e a institucionalização de uma nova experiência de educação no Brasil. ANPED, 2013.

NASCIMENTO, Beatriz. Kilombo e memória comunitária: um estudo de caso. Rio de janeiro, Estudos Afro-Asiáticos 6-7, 1982c, pp. 259-265.

SANTOS, Laura Maria. In: SOLARI, Patrícia (org.). Vivência de saberes: Quilombo Campinho da Independência. Paraty, RJ: UNESCO, 2008.

SOUZA, Vanessa Marcondes. LOUREIRO, Carlos Frederico Bernardo. A educação formal enquanto estratégia de luta dos povos caiçaras da Península da Juatinga, Paraty/RJ. Revista Cadernos de Educação. № 51, 2015-UFPeL. 
Quilombo Campinho Da Independência, Paraty (Rj): território étnico e a luta por uma educação diferenciada

WALSH, Catherine; GARCÍA, Juan. "El pensar del emergente movimiento afroecuatoriano: Reflexiones (des) de un processo". In: MATO, Daniel (org.). Estudios y Otras Prácticas Intelectuales Latinoamericanas en Cultura y Poder. Caracas:

CLACSO, 2002, pp. 317-326.

Etnoeducación e interculturalidad en perspectiva decolonial. In: Seminario Internacional Etnoeducacion e Interculturalidad, 4., 2011, Lima, Perú. Anais... Lima, Perú: CEDET, 2011.

. Interculturalidad y (de)colonialidad: Perspectivas críticas y políticas. Visão Global, Joaçaba, v. 15, n. 1-2, p. 61-74, jan./dez. 2012.

. Notas pedagógicas a partir das brechas decoloniais. In: CANDAU, Vera Maria (Org.). Interculturalizar, descolonizar, democratizar: uma educação "outra"? Rio de Janeiro: 7 Letras, 2016, pp. 64-75. 